\title{
Interhemispheric observations of the ionospheric signature of tail reconnection during IMF-northward non-substorm intervals
}

\author{
A. Grocott, T. K. Yeoman, S. E. Milan, and S. W. H. Cowley \\ Department of Physics \& Astronomy, University of Leicester, Leicester LE1 7RH, UK \\ Received: 13 January 2005 - Revised: 27 April 2005 - Accepted: 3 May 2005 - Published: 28 July 2005
}

\begin{abstract}
This paper presents the first interhemispheric radar observations interpreted as the ionospheric response to tail reconnection during IMF-northward non-substorm intervals. SuperDARN measurements of plasma convection in the nightside ionospheres of both hemispheres, taken on 21-22 February and 26-27 April 2000, show bursts of flow in the midnight sector which are understood to be characteristic of such phenomena. Upstream interplanetary magnetic field data confirm that the field orientation at the dayside magnetopause was northwards, but with a significant IMF $B_{y}$ component (negative during the first interval, positive during the second), for many hours prior to the bursts being observed. During the $B_{y}$-negative interval the bursts were directed westwards in the Northern Hemisphere and eastwards in the Southern Hemisphere; during the $B_{y}$-positive interval their directions were reversed. These two asymmetries between the different orientations of IMF $B_{y}$ and between the two hemispheres are key to our understanding of the magnetospheric phenomenon responsible for generating the bursts. They provide further evidence in support of the idea that the bursts are a result of reconnection in an asymmetric tail under the prolonged influence of IMF $B_{y}$. Concurrent data from ground magnetometers and geosynchronous satellites confirm that the bursts have no associated substorm characteristics, consistent with previous studies.
\end{abstract}

Keywords. Ionosphere (Plasma convection; Ionospheremagnetosphere interactions) - Magnetospheric Physics (Magnetotail)

\section{Introduction}

It has long been supposed that the major episodes of reconnection and open flux destruction in the tail take place during magnetospheric substorms (Hones, 1979; Baker et al., 1996). Geotail observations, for example, have shown that recon-

Correspondence to: A. Grocott

(ag27@ion.le.ac.uk) nection typically begins in the dusk sector plasma sheet at down-tail distances of $\sim 20-30 R_{E}$ a few minutes before the onset of expansion phase signatures on the ground, and expands to encompass a significant fraction of the dusk and midnight sector tail (Nagai et al., 1998; Nagai and Machida, 1998; Petrukovich et al., 1998; Machida et al., 1999). In the ionosphere this is manifest as large-scale twin-vortex flows which are excited in the nightside hemisphere (Cowley and Lockwood, 1992, and references therein) as newly closed flux exits the polar cap and is accelerated back towards the dayside. A typical substorm will involve a total flux closure of $\sim 0.25 \mathrm{GWb}$, representing approximately $50 \%$ of the amount of open flux present before onset (Milan et al., submitted, $2005^{1}$ ).

When the interplanetary field points north, it is well established that Dungey-cycle flow and substorm activity are reduced (e.g. Fairfield and Cahill, 1966; Reiff et al., 1981). At the same time, high-latitude reconnection between lobe field lines and the IMF begins, exciting additional flow cells, particularly on the dayside (e.g. Dungey, 1963; Russell, 1972; Reiff and Burch, 1985; Bristow et al., 1998). However, observations in the dayside ionosphere suggest that open flux tube production does not switch off entirely until the clock angle falls below $\sim 30^{\circ}-40^{\circ}$ (e.g. Sandholt et al., 1998a, b) such that during intervals of northward, but $B_{y}$-dominated IMF, both open field line (lobe) and closed field line reconnection may be taking place (Nishida et al., 1998). On the nightside, the response to a modest but steady dayside driving under these conditions is readily observable. Taguchi (1992), for example, reported Magsat observations of IMF $B_{y}$-controlled field-aligned currents near the midnight auroral oval. Taguchi et al. (1994) and Taguchi and Hoffman (1996) went on to associate these currents with DE-2 observations of azimuthal plasma convection, which

\footnotetext{
${ }^{1}$ Milan, S. E., Wild, J. A., Grocott, A., and Draper, N. C.: Spaceand ground-based investigations of solar wind-magnetosphereionosphere coupling, COSPAR 2004 proceedings, submitted to Adv. Space Res., 2005.
} 


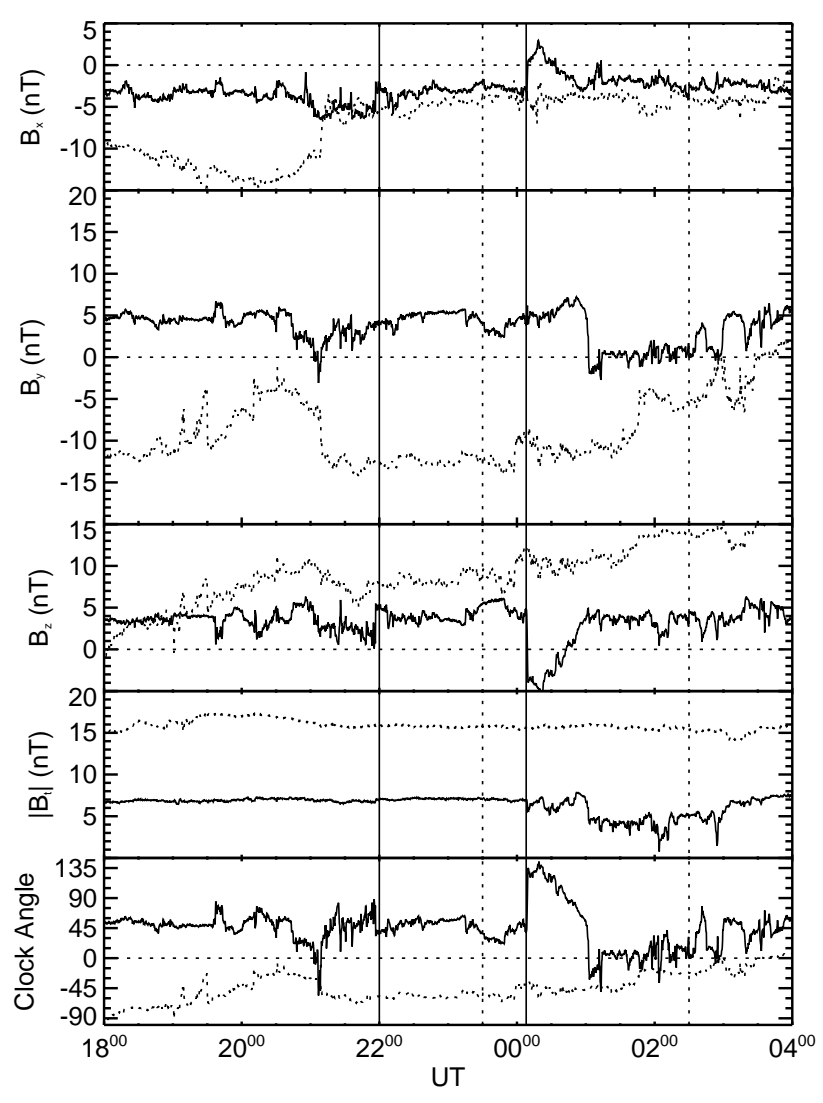

Fig. 1. Upstream interplanetary observations from the ACE spacecraft for 18:00-04:00 UT on 21/22 February 2000 (dotted lines, Interval-) and 26/27 April 2000 (solid lines, Interval+), lagged by 71 and $67 \mathrm{~min}$, respectively, to account for the propagation delay to the ionosphere. The top three panels show IMF data in GSM co-ordinates, and the bottom two panels show the field magnitude and clock angle. The clock angle is defined with respect to north, such that $0^{\circ}$ corresponds to a transverse field purely in the $+z$ direction (northward), $\pm 90^{\circ}$ to $\pm y$ (respectively) and $\pm 180^{\circ}$ to $-z$ (southward). The vertical lines indicate key times described in the text.

they explained in terms of reconnection in a twisted tail following long steady intervals of large IMF $B_{y}$. Nishida et al. (1998) proposed a unified model of magnetotail convection based on Geotail data which elaborates on the model proposed by Taguchi et al. (1994) and Taguchi and Hoffman (1996) and relates the nightside flows to the concurrent dayside reconnection which drives them. Other, more complex models have also been proposed (e.g. Tanaka, 1999; Watanabe et al., 2004) which consider alternative configurations for the dayside reconnection, and subsequent magnetotail reconnection, that may occur during a wide variety of northward IMF clock angles.

Recently, Senior et al. (2002) and Grocott et al. (2003, 2004) have reported SuperDARN observations of large-scale bursty flows in the nightside ionosphere during extended intervals of $90^{\circ}>\mathrm{IMF}$ clock angle $>45^{\circ}$. These flows have a recurrence time of $\sim 1 \mathrm{~h}$, with substructure on tens of minutes time scales. They take the form of surges of azimuthal "return" flow in the dawn and dusk convection cells, several degrees wide in latitude, consistent with the flows observed by Taguchi et al. (1994) and Taguchi and Hoffman (1996). No evidence of substorm signatures in the tail magnetic field or particle fluxes at geosynchronous distances seem to accompany these bursts, yet evidence in the ionosphere for flux closure is apparent at rates of $\sim 30-50 \mathrm{kV}$ (Grocott et al., 2003; Milan et al., 2005; Milan et al., submitted, $2005^{1}$ ). Over several hours these bursts of "tail reconnection during IMFnorthward non-substorm intervals", or TRINNIs, are therefore clearly capable of closing a significant fraction of a GWb of flux. Whilst evidently not as intense as substorms (auroral brightnesses $\sim 100$ times weaker than in substorm expansion phases have been reported by, e.g. Milan et al., submitted, $2005^{1}$ ) TRINNIs are, nevertheless, an extremely important phenomenon for flux transport in the tail. However, owing to a dearth of observations to date, very little is understood about them and their driving mechanisms.

One significant hole in our understanding comes from a lack of direct interhemispheric observations. Grocott et al. (2004), following the work of Nishida et al. (1998) discussed above, suggested that the ionospheric signature of a TRINNI was caused by the reconfiguration of an asymmetric tail resulting from prolonged dayside reconnection between terrestrial field lines and a $B_{y}$-dominated IMF. By the time tail field lines reconnected some distance downtail they would have ionospheric footprints which were significantly displaced in azimuth in opposite hemispheres. The untwisting of the tail field after reconnection could explain the fast azimuthal flows in the ionosphere, only if oppositely directed flows were driven in opposite hemispheres. This paper shows that the nature of the bursts in the Southern Hemisphere is indeed opposite to that of those in the north, corroborating previous observations as well as the theory mentioned above (which is discussed in more detail in Sect. 4). Two intervals are presented here, one during which IMF $B_{y}$ was negative $(21 / 22$ February 2000 , hereafter referred to as Interval -$)$ and one where IMF $B_{y}$ was positive (26/27 April 2000, Interval +).

\section{Instrumentation}

The main instrumentation employed in this study is that of the Super Dual Auroral Radar Network (SuperDARN) (Greenwald et al., 1995). Data from the twelve HF radars which comprised the Northern and Southern Hemisphere components of the network at the time of the intervals discussed in this study have been used to derive large scale maps of the high-latitude convection using the "Map Potential" model (Ruohoniemi and Baker, 1998). The lineof-sight velocities are mapped onto a polar grid, and used to determine a solution for the electrostatic potential which is expressed in spherical harmonics up to sixth order. The equipotentials of the solution represent the plasma streamlines of the modelled convection pattern. Information from 
the statistical model of Ruohoniemi and Greenwald (1996), parameterised by concurrent IMF conditions, is used to stabilise the solution where no data are available. A HeppnerMaynard boundary, determined from the line-of-sight velocity data, is also used to constrain the convection pattern at lower latitudes (Heppner and Maynard, 1987; Shepherd and Ruohoniemi, 2000). The flow vectors which will be shown superposed on the electric equipotentials are derived using the SuperDARN line-of-sight velocity measurements with the transverse velocity component provided by the spherical harmonic fits.

IMF conditions for each study interval were measured by the MAG instrument (Smith et al., 1999) onboard the ACE spacecraft (Stone et al., 1998). During Interval- ACE was located upstream at GSM coordinates $(\mathrm{X}, \mathrm{Y}, \mathrm{Z})=(239,-30,10) R_{E}$ and during Interval + it was located at $(\mathrm{X}, \mathrm{Y}, \mathrm{Z})=(223,2,-21) R_{E}$ (with negligible movement over each interval). Solar wind data obtained by the SWEPAM instrument (McComas et al., 1998) were also used to estimate the propagation delay of field changes from ACE to the dayside ionosphere using the algorithm of Khan and Cowley (1999). This was found to be $71 \pm 7 \mathrm{~min}$ for Interval - and $67 \pm 5 \mathrm{~min}$ for Interval + and has been used to lag the appropriate ACE IMF data displayed here.

\section{Observations}

\subsection{Upstream interplanetary conditions}

Figure 1 shows the lagged ACE interplanetary magnetic field data in GSM coordinates from 18:00-04:00 UT from both Interval - (dotted lines) and Interval + (solid lines). The scale of each panel is the same for both intervals with the range for IMF $B_{y}$ doubled to account for the opposite senses. The vertical lines indicate the times of SuperDARN flow maps (discussed below), again, dotted for Interval - and solid for Interval + . When considering the time axis in this figure it is important to remember that the data have only been lagged to the dayside ionosphere, whereas the flow features we are interested in occur on the nightside (and are understood to be a result of reconnection in the tail). Since the tail neutral line may be many $100 R_{E}$ downstream (Richardson et al., 1989; Watanabe et al., 1998) it will be the IMF conditions from some hours earlier which determined the nature of the tail dynamics and data are therefore shown from $4 \mathrm{~h}$ prior to the intervals of interest.

During both intervals IMF $B_{x}$ was predominantly negative, strongly so $(\sim-10 \mathrm{nT})$ for the first part of Interval - and weakly so $(>-5 \mathrm{nT})$ at most other times. IMF $B_{y}$ was, by definition, positive for the most part during Interval + and negative during Interval-. It is worth noting that the magnitude of IMF $B_{y}$ was greater for Interval - than Interval + (as was the magnitude of IMF $B_{z}$ and the total field). It is also apparent that IMF $B_{y}$ dropped to near zero towards the end of Interval +, although for reasons discussed above this is likely to have occurred too late on in the interval to be of any consequence. Whilst predominantly positive, IMF $B_{z}$ made a brief negative excursion towards the end of the same interval (coincident with a pressure pulse seen in the SWEPAM data of $\sim 1.3-5.4 \mathrm{nPa}$, not shown) and in this case the change coincided with an enhancement in the nightside flow (see next section). In general, the field remained steadier during Interval -, with a total field strength of $\sim 15 \mathrm{nT}$ and clock angle of $\sim-45^{\circ}$. Interval + had a field which, whilst weaker, had a similar clock angle magnitude to Interval - for the most part, with some pressure pulse-related variability towards the end.

\subsection{SuperDARN observations of the nightside ionospheric} flow

Figure 2 shows four pairs of maps of the nightside highlatitude ionospheric flow observed by the SuperDARN radars, with midnight at the bottom and dusk to the left. The numbers on the contours indicate the ionospheric electric potentials in $\mathrm{kV}$ (discussed in Sect. 2) which are negative at dusk (clockwise flow) and positive at dawn (anticlockwise flow). The total transpolar voltage is also shown in the bottom right corner of each panel. The flow vectors are colour coded according to the velocity colour bar shown on the right, with the vector length scale also being indicated in the bottom left of each panel. Panels (a-d) are from Interval - and panels $(\mathrm{e}-\mathrm{h})$ are from Interval + . Each pair of panels shows the Northern and Southern Hemisphere flows for the times indicated by the vertical lines on Fig. 1. These times are also displayed at the top of each flow map-pair.

Panels (a) and (c) then show the Northern Hemisphere flows during the $B_{y}$-negative interval. In each case, the dominant flow feature is a strong (of order $\sim 1000 \mathrm{~ms}^{-1}$ ) westward burst in the midnight sector which resembles those bursts discussed by Grocott et al. (2003). The burst in panel (a) appears to be slightly further round towards dusk, forming part of a more "usual" flow cell. The burst in panel (c), which occurred $\sim 3 \mathrm{~h}$ later forms part of a more distorted dusk flow cell which covers much of the polar cap. In both cases, the flows out of the polar cap into the nightside auroral zone are shifted towards dawn. Panels (e) and (g) show the Northern Hemisphere flows during the $B_{y}$-positive interval. In this case, the flows out of the polar cap are shifted towards dusk, with bursts of return flow which have the opposite direction to those for $B_{y}$-negative (as found by Grocott et al., 2004), and a slightly reduced flow magnitude $\left(\sim 600-800 \mathrm{~ms}^{-1}\right)$.

It can be seen by examining panels (b), (d), (f) and (h) that the coincident Southern Hemisphere flows similarly take the form of high speed bursts. It is also clear that these Southern Hemisphere counterparts have the opposite east-west flow asymmetry, both in the location of the flows out of the polar cap, and in the direction of the return flows. In other words, northern $B_{y}$-positive bursts resemble southern $B_{y}$-negative busts, and vice versa. Again, the bursts during Interval(panels (b) and (d)) are faster than those from Interval + (panels (f) and (h)). These observations will be discussed further in the next section. 

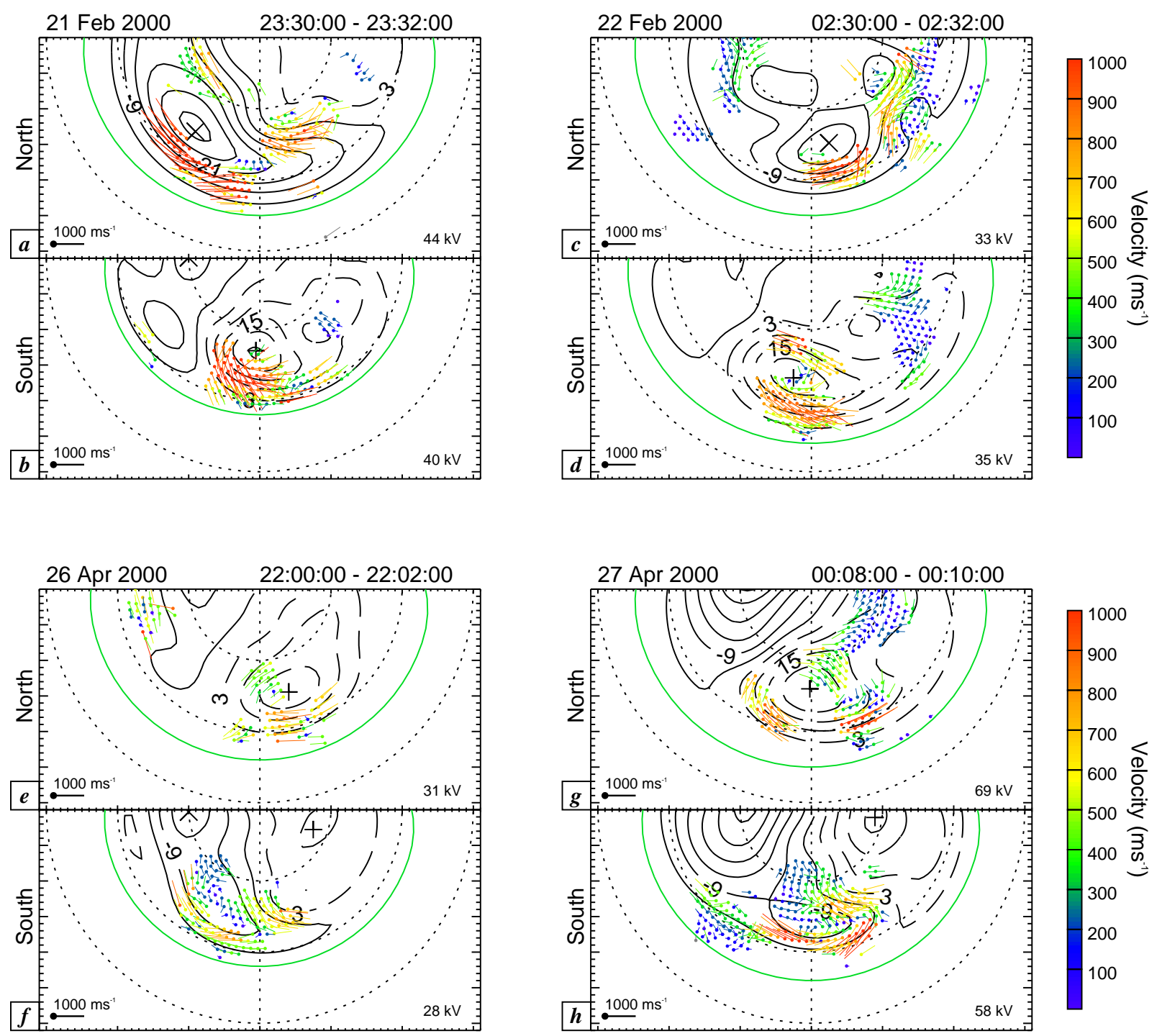

Fig. 2. Streamlines and vectors of the nightside ionospheric flows derived from SuperDARN velocity measurements. These data are shown on geomagnetic latitude-MLT grids, with midnight at the bottom and dusk to the left. Each map-pair corresponds to the vertical lines in Fig. 1, the times of which are indicated in the top right-hand corner of each pair. The transpolar voltage is indicated in the bottom right-hand corner of each map and the colour bars indicate the magnitude of the flow vectors.

\section{Discussion}

The observations presented above are consistent with those reported by Grocott et al. (2003, 2004) in showing the ionospheric signatures of TRINNIs. It is worth noting that ground magnetometer data and LANL geosynchronous particle data (not shown) are also consistent, showing no evidence of substorm activity during the intervals. The present observations are unique, however, in that they also show that these signatures, which have previously been observed in the Northern Hemisphere alone, are also evident in Southern Hemisphere data concurrently. They also show that the Southern Hemisphere bursts have the opposite direction to those in the north, corroborating the theory on their origin which is revisited below.

\subsection{Magnetospheric morphology}

It now seems clear that these night side IMF $B_{y}$ flow phenomena are related to similar phenomena that occur on the dayside in the region of the cusp. There you also see $B_{y}$-dependent east-west flows downstream of the reconnection site which are opposite in opposite hemispheres. These are associated with newly-opened flux tubes, poleward of the open-closed field line boundary, that are being pulled sideways by the field tension force (the Svalgaard-Mansurov effect) (Svalgard, 1973). This tension force causes the field lines to enter the lobes at the magnetopause on opposite sides of the tail in the two hemispheres putting an asymmetry (or twist) into the tail lobes. This is illustrated in Fig. 3, which shows a schematic representation of one possible explanation 
for "TRINNI" field line topology responsible for producing the flow bursts (based on Nishida et al., 1998). Panel (a) shows a view looking down on the Earth's poles from the north with noon to the top and dusk to the left. The southern pole is thus viewed as if looking through the Earth. The open-closed field line boundary is shown as a dashed line and the reconnection line is dot-dashed. For positive IMF $B_{y}$, the black solid arrowed curves show the convection streamlines for the Northern Hemisphere and the grey ones for the Southern Hemisphere (the opposite is true for negative IMF $B_{y}$ ). Tail field lines are represented by the straight lines which connect the two hemispheres via the reconnection line. When these field lines reconnect they therefore produce twisted closed flux tubes like those shown in panel (b). This shows the corresponding view towards the Earth from the tail for the 2 orientations of IMF $B_{y}$. The twisted neutral sheet is indicated by the dashed line and the newly reconnected field lines $(\mathbf{B})$ are indicated. The effect we see in the ionosphere is the untwisting of these closed flux tubes in the return sunward flow. This is indicated in panels (a) and (b) by the thick arrowed curves.

It is important to appreciate that the bursts in each hemisphere are not geomagnetically conjugate. Consider a field line, immediately after being closed, with its footprints at points " $x$ " just equatorward of the open-closed field line boundary. Its return path to the dayside can be one of two ways, i.e. via dusk or dawn. If it goes via dusk then (for, e.g. the IMF $B_{y}$-positive case) it will form part of a Southern Hemisphere flow burst, whereas if it goes via dawn then it forms part of a Northern Hemisphere flow burst. Which is the case is likely to depend on where the field lines cross the equatorial plane. Roughly, if this is pre- (post-) midnight, the field line will map to the burst in the southern (northern) hemisphere, as the field lines contract towards the Earth and are diverted via dusk (dawn) around it.

\subsection{Flow burst magnitude}

The relationship between nightside dynamics and the history of prior dayside activity is further illustrated by considering the magnitude of the flow bursts. Referring back to Fig. 2, it was noted above that the magnitude of the flow velocities during Interval + are of lower magnitude than those for Interval-. It does not appear to be a common feature of $B_{y}$ positive flow bursts to be of lower velocity (Grocott et al. (2004) reported bursts in excess of $1000 \mathrm{~ms}^{-1}$ during $B_{y}$-positive intervals) but may, therefore, be related to differences in the IMF driving conditions of the previous few hours. Indeed, it was also noted above that the magnitudes of IMF $B_{y}, B_{z}$, and the total field were larger during Interval-. A higher rate of dayside reconnection which would be expected to occur in the presence of a stronger IMF (Freeman et al., 1993) might reasonably be expected to lead to more intense tail driven convection.
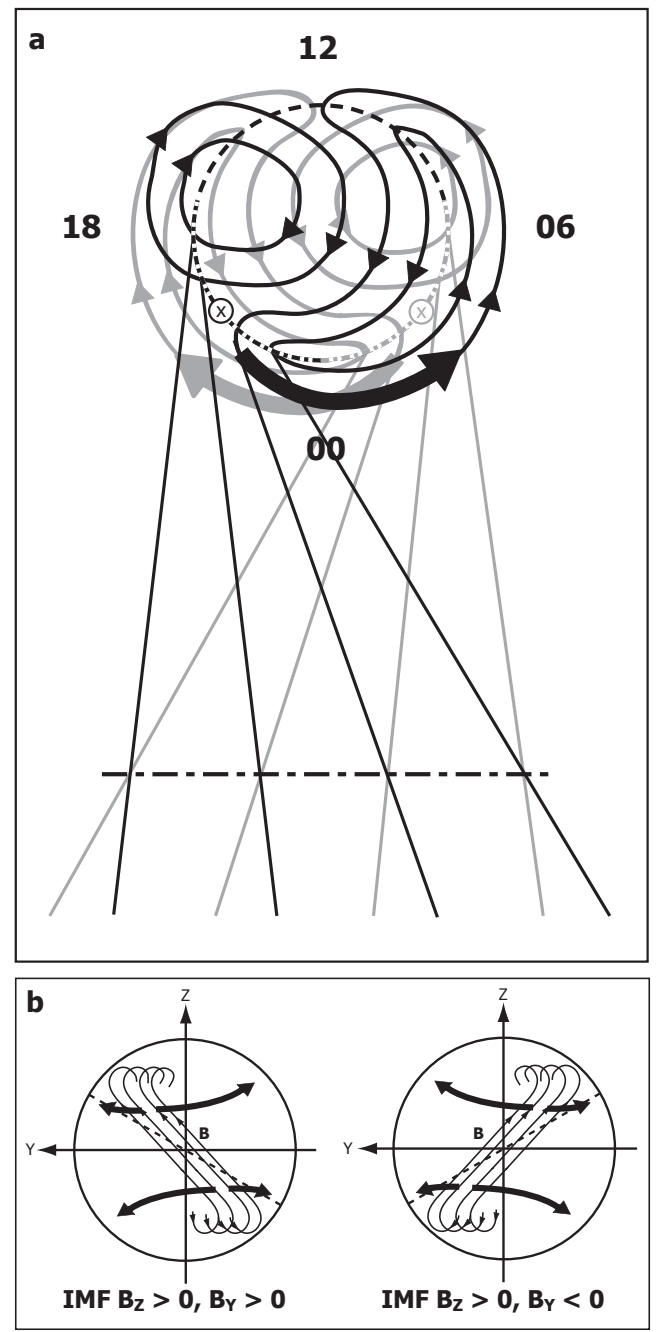

Fig. 3. Schematic representation of "TRINNI" field line topology in the magnetotail responsible for producing the flow bursts. (a) A view looking down on the Earth's poles from the north with noon to the top and dusk to the left. The southern pole is thus viewed as if looking through the Earth. The open-closed field line boundary is shown as a dashed line and the reconnection line is dot-dashed. The solid arrowed curves show the convection streamlines for the northern (southern) IMF $B_{y}$-positive (-negative) case in black and the southern (northern) IMF $B_{y}$-positive (-negative) case in grey. The thick large arrows depict the flow bursts themselves. Tail field lines are represented by the straight lines which connect the two hemispheres via the reconnection line. (b) The corresponding view towards the Earth from the tail for the 2 orientations of IMF $B_{y}$. The twisted neutral sheet is indicated by the dashed line and newly reconnected (closed) field lines $(\mathbf{B})$ are indicated. Convection return flows are shown by arrows (after Nishida et al., 1998; Grocott et al., 2004; Milan et al., 2005).

\subsection{Time evolution of the flow bursts}

An additional point of interest concerns the time evolution of the flows in each hemisphere. This is not at all obvious from the discussion of individual flow maps and so a time series of the flows is presented in Fig. 4. The solid curves show the 

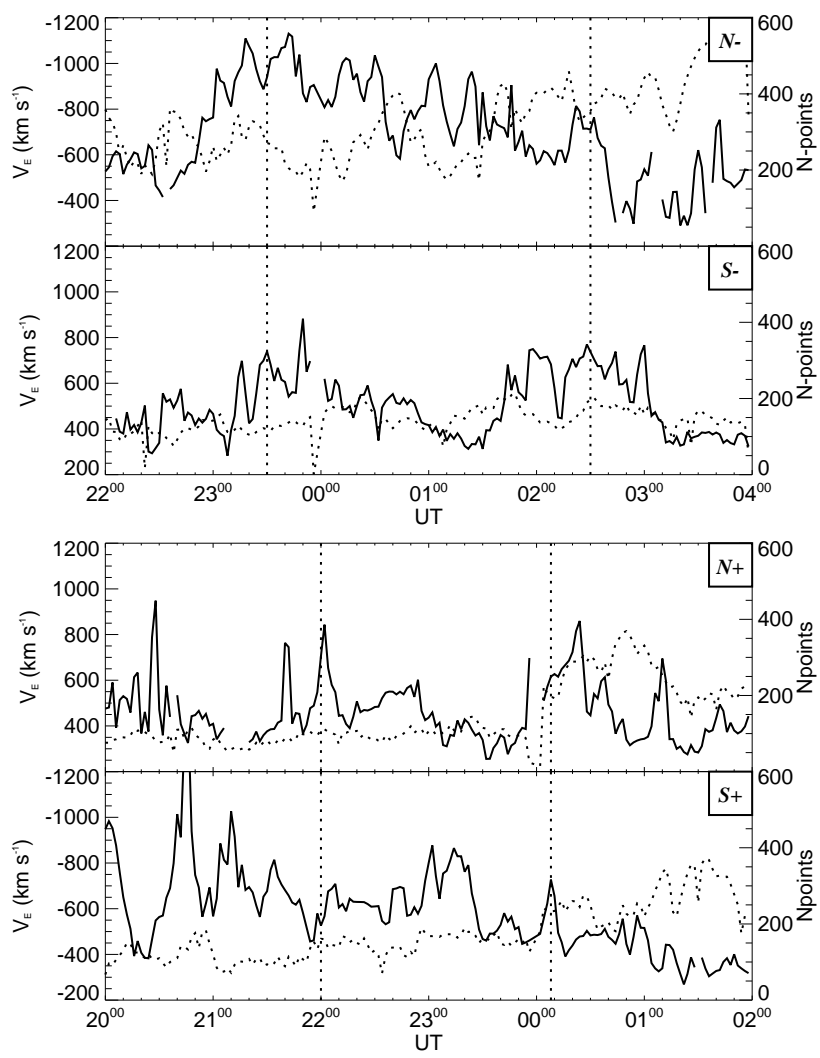

Fig. 4. Flow measurement time-series obtained from the SuperDARN radar observations and the "Map Potential" algorithm. The solid lines show the peak east-west ionospheric flow speed from the midnight sector (left hand axis) and the dotted lines show the number of radar data points in the Map Potential fit (right hand axis). The icons in the top right-hand corner of each panel indicate the hemisphere (N/S) and the Interval (+/-). The vertical lines are the same as those in Fig. 1.

peak eastward flow velocity in the midnight sector for each of the two intervals (+/-), for each hemisphere (N/S) and the dotted curves indicate the number of radar data points used in the Map Potential fit. The vertical dotted lines are as in Fig. 1. It is immediately evident that the flows are quite variable during each interval, with enhancements over the background level of many $100 \mathrm{~s} \mathrm{~ms}^{-1}$. It also appears that not all peaks in the flow are actually coincident in both hemispheres. In some cases, e.g. at 23:00 UT in Interval +, an enhancement in the Northern Hemisphere flows seems to proceed one in the Southern Hemisphere by $\sim 20 \mathrm{~min}$. This seems to be supporting the idea discussed in Sect. 4.1 concerning the lack of geomagnetic conjugacy between the northern and southern bursts. Since different field lines are mapping to bursts in each hemisphere there is no constraint on the bursts being simultaneous.

Whilst it is clear that IMF $B_{y}$ controls the asymmetry in the direction of the northern and southern bursts, it is not so obvious what controls the asymmetry in the timing. It is interesting to note the large negative IMF $B_{x}$ present, in particular in Interval +, which could play a role here. Interhemispheric asymmetries in lobe reconnection, for example, are believed to be due, in part, to IMF $B_{x}$ (e.g. Lockwood and Moen, 1999) since reconnection in one lobe can occur between the IMF and pre-existing open flux. Moderate IMF $B_{x}$ effects have also been observed in relation to, for example, the location of the polar cap and cusp (Cowley et al., 1991). Although the reconnection of closed flux with the IMF (as is believed to be occurring here) obviously produces the same amount of open flux in both hemispheres irrespective of the location on the magnetopause at which it is occurring, the consequent field line geometry imparted on the two tail lobes may well be different. Any north-south asymmetry in the prior dayside reconnection could therefore be responsible for the asymmetry in subsequent tail reconnection. A study of the interhemispheric statistics of these flow bursts and their associated IMF conditions (currently in progress) will hopefully reveal more about their generation mechanism.

\subsection{Radar data coverage}

The issue of radar data coverage is perhaps worth commenting on in more detail, specifically regarding its limited nature and time-variability. Although coverage is limited, for the most part it is relatively consistent. Whilst we might not, therefore, want to rely too heavily on the global convection pattern implied by the Map Potential model, we can be confident that the localised flow signatures indicated by the radar data are real for two reasons. Firstly the statistical model of Ruohoniemi and Greenwald (1996), used in the Map Potential fitting process, contains no information regarding the TRINNI related flow bursts. Any evidence of them must, therefore, be coming from the radar data itself. Secondly, there is rarely any correlation between variations in the flow speed and the number of radar data points. This suggests that the variations are real and not just a result of fluctuating data coverage. There is one exception to this, which can be seen at the time of the second vertical line in Fig. 4, Interval +. Here we see an enhancement to the flows in both hemispheres coincident with an enhancement in the amount of radar data. This enhancement also coincided with a brief negative excursion in IMF $B_{z}$ (as mentioned above) and the start of a substorm growth phase (evinced in ground magnetometer and LANL geosynchronous spacecraft data, not shown). It is possible, therefore, that these changes in geophysical activity may have had some bearing on the nature of the nightside flows, although it is unlikely that they would have significantly altered the magnetotail dynamics over such a short timescale. The sudden change in interplanetary conditions may, however, have provided a trigger for this enhancement, as suggested above. In any case, these concerns should be the subject of future work, and do not affect the overall conclusions of the present study.

Finally, the possibility does exist that the location of the data coverage could change, such that flows appear to come and go even though the overall amount of data remained constant. The likelihood of this is small, however, for a number 
of reasons. Firstly, the occurrence of radar scatter is not random, but is naturally related to the ionospheric conditions at the time. Where data does disappear, it may be the case that this is a result of a physical change with respect to the mechanism which is driving the flows. In effect, therefore, an absence of scatter could simply be indicative of an absence of activity. This is not strictly true, of course, since propagation effects could also cause the scatter to disappear, although this itself can be ruled out if scatter at further ranges is still present. Nevertheless, the time-series curve plotted in Fig. 4 is only drawn where there are at least two data points present. A complete disappearance of data coverage will not, therefore, be interpreted as a real variation in the flow. Lastly, and perhaps most basically, an inspection of the flow maps for the whole of each interval studied suggests that there is indeed relatively good consistency in the location of the data throughout.

\section{Summary}

This paper has shown the first interhemispheric radar observations interpreted as the ionospheric response to tail reconnection during IMF-northward non-substorm intervals. It is found that the bursts of flow which have been previously observed in the Northern Hemisphere are also apparent in the Southern Hemisphere. The simultaneous flows have the opposite east-west direction in each hemisphere, supporting the theory discussed above on the bursts' origin. A more detailed look at the nature of the flows suggests that whilst the longer-timescale effects of the TRINNIs are apparent in both hemispheres, there is some variability in the flow which is not simultaneous. A statistical study currently in progress should elucidate this matter further, as well as providing the means to categorise the TRINNI phenomenon in terms of the governing IMF conditions and the amount of flux closure involved.

Acknowledgements. We would like to thank the PIs of the SuperDARN radars for provision of the radar data employed in this study. The data employed were from radars funded by the research funding agencies of Canada, France, Japan, South Africa, Australia, the UK, and USA. We would also like to thank R. J. Barnes of the Johns Hopkins University Applied Physics Laboratory for provision of the "Map-Potential" algorithm software. For provision of ACE magnetometer data we thank N. Ness and C. Smith of the Bartol Research Institute. A. Grocott was supported during this study by PPARC grant PPA/G/O/2003/00013. SuperDARN operations at the University of Leicester are supported by PPARC grant PPA/R/R/1997/00256.

Topical Editor M. Pinnock thanks M. Watanabe and G. Abel for their help in evaluating this paper.

\section{References}

Baker, K. B. and Wing, S.: A new magnetic coordinate system for conjugate studies at high latitudes, J. Geophys. Res., 94, 9139_ 9143, 1989.
Bristow, W. A., Ruohoniemi, J. M., and Greenwald, R. A.: Super Dual Auroral Radar Network observations of convection during a period of small-magnitude northward IMF, J. Geophys. Res, 103, 4051-4062, 1998.

Cowley, S. W. H., Morelli, J. P., and Lockwood, M.: Dependence of convective flows and particle precipitation in the high-latitude dayside ionosphere on the $\mathrm{X}$ and $\mathrm{Y}$ components of the interplanetary magnetic field, J. Geophys. Res., 96, 5557-5564, 1991.

Cowley, S. W. H. and Lockwood, M.: Excitation and decay of solar wind-driven flows in the magnetosphere-ionosphere system, Ann. Geophys., 10, 103-115, 1992.

Dungey, J. W.: The structure of the exosphere, or, adventures in velocity space, Geophysics, The Earth's Environment, edited by: Dewitt, C., Hieblot, J., and Lebau, A., Gordon and Breach, Newark, N. J., 505, 1963.

Fairfield, D. H. and Cahill Jr., L.J.: Transition region magnetic field and polar magnetic disturbances, J. Geophys. Res, 71, 155-169, 1966.

Freeman, M. P., Farrugia, C. J., Burlaga, L. F., Hairston, M. R., Greenspan, M. E., Ruohoniemi, J. M., and Lepping, R. P.: The interaction of a magnetic cloud with the Earth: Ionospheric convection in the northern and southern hemispheres for a wide range of quasi-steady interplanetary magnetic field conditions, J. Geophys. Res., 98, 7633-7655, 1993.

Greenwald, R. A., Baker, K. B., Dudeney, J. R., Pinnock, M., Jones, T. B., Thomas, E. C., Villain, J.-P., Cerisier, J.-C., Senior, C., Hanuise, C., Hunsucker, R. D., Sofko, G., Koehler, J., Nielsen, E., Pellinen, R., Walker, A. D. M., Sato, N., and Yamagishi, H.: DARN/SuperDARN: A global view of the dynamics of high-latitude convection, Space Sci. Rev., 71, 761-796, 1995.

Grocott, A., Cowley, S. W. H., and Sigwarth, J. B.: Ionospheric flows and magnetic disturbance during extended intervals of northward but $B_{y}$-dominated IMF, Ann. Geophys., 21, 509-538, 2003,

SRef-ID: 1432-0576/ag/2003-21-509.

Grocott, A., Badman, S. V., Cowley, S. W. H., Yeoman, T. K., and Cripps, P. J.: The influence of IMF $B_{y}$ on the nature of the nightside high-latitude ionospheric flow during intervals of positive IMF B B $_{z}$, Ann. Geophys., 22, 1755-1764, 2004,

SRef-ID: 1432-0576/ag/2004-22-1755.

Heppner, J. P. and Maynard, N. C.: Empirical high-latitude electric field models, J. Geophys. Res., 92, 4467-4489, 1987.

Hones, Jr., E.W.: Transient phenomena in the magnetotail and their relation to substorms, Space Sci. Rev., 23, 393-410, 1979.

Khan, H., and Cowley, S. W. H.: Observations of the response time of high latitude ionospheric convection to variations in the interplanetary magnetic field using EISCAT and IMP-8 data, Ann. Geophys., 17, 1306-1335, 1999,

SRef-ID: 1432-0576/ag/1999-17-1306.

Machida, S., Miyashita, Y., Ieda, A., Nishida, A., Mukai, T., Saito, Y. and Kokubun, S.: Geotail observations of flow velocity and north-south magnetic field variations in the near and mid-distant tail associated with substorm onsets, Geophys. Res. Lett., 26, 635-638, 1999.

McComas, D. J., Bame, S. J., Barker, P., Feldman, W. C., Phillips, J. L., Riley, P., and Griffee, J. W.: Solar Wind Electron Proton Alpha Monitor (SWEPAM) for the Advanced Composition Explorer, Space Sci. Rev., 86, 563-612, 1998.

Milan, S. E., Hubert, B., and Grocott, A.: Formation and motion of a transpolar arc in response to dayside and nightside reconnection, J. Geophys. Res., 110, doi:10.1029/2004JA010835, 2005.

Nagai, T. and Machida, S.: Magnetic reconnection in the near-earth 
magnetotail, in: New Perspectives on the Earth's Magnetotail, edited by: Nishida, A., Baker, D. N., and Cowley, S. W. H., Geophys. Mono. 105, AGU, Washington, D.C., 211, 1998.

Nagai, T., Fujimoto, M., Saito, Y., Machida, S., Teresawa, T., Nakamura, R., Yamamoto, T., Mukai, T., Nishida, A., and Kokubun, S.: Structure and dynamics of magnetic reconnection for substorm onsets with Geotail observations, J. Geophys. Res., 103, 4419-4440, 1998.

Nishida, A., Mukai, T., Yamamoto, T., Kokubun, S., and Maezawa, K.: A unifield model of the magnetotail convection in geomagnetically quiet and active times, J. Geophys. Res., 103, 4409-4418, 1998.

Petrukovich, A. A., Sergeev, V. A., Zleneyi, L. M., Mukai, T., Yamamoto, T., Kokubun, S., Shiokawa, K., Deehr, C. S., Budnick, E. Y., Büchner, J., Fedorov, A. O., Grigorieva, V. P., Hughes, T. J., Pissarenko, N. F., Romanov, S. A., and Sandahl, I.: Two spacecraft observations of a reconnection pulse during an auroral breakup, J. Geophys. Res., 103, 47-59, 1998.

Reiff, P. H. and Burch, J. L.: IMF $B_{y}$-dependent plasma flow and Birkeland currents in the dayside magnetosphere, 2. A global model for northward and southward IMF, J. Geophys. Res., 90, 1595-1609, 1985.

Reiff, P. H., Spiro, R. W., and Hill, T. W.: Dependence of polar cap potential drop on interplanetary parameters, J. Geophys. Res, 86, 7639-7648, 1981.

Richardson, I. G., Owen, C. J., Cowley, S. H. W., Galvin, A. B., Sanderson, T. R., Scholer, M., Slavin, J. A., Zwickl, R. D.: ISEE 3 observations during the CDAW 8 intervals: Case studies of the distant geomagnetic tail covering a wide range of geomagnetic activity, J. Geophys. Res., doi:10.1029/89JA00264, 1989.

Ruohoniemi, J. M. and Greenwald, R. A.: Statistical patterns of high-latitude convection obtained from Goose Bay HF radar observations, J. Geophys. Res., 101, 21 743-21 763, 1996.

Ruohoniemi, J. M. and Baker, K. B.: Large-scale imaging of highlatitude convection with Super Dual Auroral Radar Network HF radar observations, J. Geophys. Res., 103, 20 797-20 811, 1998.

Russell, C. T.: The configuration of the magnetosphere, in Critical Problems of Magnetospheric Physics, edited by: Dyer, R., Nat. Acad. of Sci., Washington, D.C., 1-16, 1972.

Sandholt, P. E., Farrugia, C. J., Moen, J., and Cowley, S. W. H.: Dayside auroral configurations: responses to southward and northward rotations of the interplanetary magnetic field, J. Geophys. Res., 103, 20 279-20 295, 1998a.
Sandholt, P. E., Farrugia, C. J., Moen, J., Noraberg, Ø., Lybekk, B., Sten, T., and Hansen, T.: A classification of dayside auroral forms and activities as a function of IMF orientation, J. Geophys. Res., 103, 23 325, 1998b.

Senior, C., Cerisier, J.-C., Rich, F., Lester, M., and Parks, G. K.: Strong sunward propagating flow bursts in the night sector during quiet solar wind conditions: SuperDARN and satellite observations, Ann. Geophys., 20, 771-786, 2002,

SRef-ID: 1432-0576/ag/2002-20-771.

Shepherd, S. G. and Ruohoniemi, J. M.: Electrostatic potential patterns in the high-latitude ionosphere constrained by SuperDARN measurements, J. Geophys. Res., 105, 23 005-23 014, 2000.

Smith, C. W., Acuña, M. H., Burlaga, L. F., L'Heureux, J., Ness, N. F., and Scheifele, J.: The ACE Magnetic Field Experiment, Space Sci. Rev., 86, 613-622, 1999.

Stone, E. C., Frandsen, A. M., Mewaldt, R. A., Christian, E. R., Margolies, D., Ormes, J. F., and Snow, F.: The Advanced Composition Explorer, Space Sci. Rev., 86, 1-22, 1998.

Svalgaard, L.: Polar cap magnetic variations and their relationship with the interplanetary magnetic sector structure, J. Geophys. Res., 78, 2064-2078, 1973.

Taguchi, S.: $B_{y}$-controlled field-aligned currents near midnight auroral oval during northward interplanetary magnetic field, J. Geophys. Res., 97, 12 231-12 243, 1992.

Taguchi, S., Sugiura, M., Iyemori, T., Winningham, J. D., and Slavin, J. A.: $B_{y}$-controlled convection and field-aligned currents near midnight auroral oval for northward interplanetary magnetic field, J. Geophys. Res., 99, 6027-6044, 1994.

Taguchi, S. and Hoffman, R. A.: Ionospheric plasma convection in the midnight sector for northward interplanetary magnetic field, J. Geomag. Geoelectr., 48, 925-933, 1996.

Tanaka, T.: Configuration of the magnetosphere-ionosphere convection system under northward IMF conditions with nonzero IMF $B_{y}$, J. Geophys. Res., 104, 14 683-14 690, 1999.

Watanabe, M., Pinnock, M., Rodger, A. S., Sato, N., Yamagishi, H. Yukimatu, A. S., Greenwald, R. A., Villain, J.-P., and Hairston, M. R.: Localised activation of the distant tail neutral line just prior to substorm onsets, J. Geophys. Res., 103, 17651 $17669,1998$.

Watanabe, M., Sofko, G. J., André, D. A., Tanaka, T., and Hairston, M. R.: Polar cap bifurcation during steady-state northward interplanetary magnetic field with $\left|\mathrm{B}_{y}\right| \sim \mathrm{B}_{z}$, J. Geophys. Res., 109, doi:10.1029/2003JA009944, 2004. 